\title{
Moderate to Severe Left Ventricular Ejection Fraction Related to Short-term Mortality of Patients with Post-cardiac Arrest Syndrome after Out-of-Hospital Cardiac Arrest
}

\author{
Kyoung Jeen Min, M.D. ${ }^{1}$, Jin Joo Kim, M.D. ${ }^{1}$, In Cheol Hwang, M.D. ${ }^{2}$, Jae Hyuk Woo, M.D. ${ }^{1}$, Yong Su Lim, M.D. ${ }^{1}$, \\ Hyuk Jun Yang, M.D. ${ }^{1}$, and Keun Lee, M.D. ${ }^{1}$
}

Department of Emergency Medicine, Gachon University Gil Medical Center, Incheon, Korea

\begin{abstract}
Background: The aim of this study was to investigate the relationships between left ventricular ejection fraction (LVEF) and mortality and neurologic outcomes with post-cardiac arrest syndrome (PCAS) after out-of-hospital cardiac arrest (OHCA).

Methods: Patients with PCAS after OHCA admitted to the intensive care unit between January 2014 and December 2015 were analyzed retrospectively.

Results: A total of 104 patients were enrolled in this study. The mean age was $54.4 \pm 15.3$ years, and 75 of the patients were male (72.1\%). Arrest with a cardiac origin was found in 55 (52.9\%). LVEF < 45\%, 45-55\%, and > 55\% was measured in 39 (37.5\%), 18 (17.3\%), and 47 (45.2\%) of patients, respectively. In multivariate analysis, severe LV dysfunction (LVEF < 45\%) was significantly related to 7-day mortality (odds ratio $3.02,95 \%$ Confidence Interval 1.01-9.0, p-value 0.047).

Conclusions: In this study, moderate to severe LVEF within 48 hours after return of spontaneous circulation was significantly related to 7-day short-term mortality in patients with PCAS after OHCA. Clinicians should actively treat myocardial dysfunction, and further studies are needed.
\end{abstract}

Key Words: echocardiography; outcome; out-of-hospital cardiac arrest.

\section{Introduction}

The mortality rate for cardiac arrest (CA) patients is still high even in the presence of initial resuscitation success.[1] CA patients frequently develop post-cardiac arrest syndrome (PCAS) immediately after the return of spontaneous circulation (ROSC), and PCAS is divided into four phases: Immediate phase (within $20 \mathrm{~min}$ ), early phase (between $20 \mathrm{~min}$ and 6 to $12 \mathrm{~h}$ ), intermediate phase (between 6 to $12 \mathrm{~h}$ and $72 \mathrm{~h}$ ) and recovery phase (beyond $72 \mathrm{~h}$ ). Interventions at the early to mid-term stages are closely associated with outcome.[2] In terms of pathophysiologic progress, PCAS compris-

Received on June 20, 2016 Revised on September 20, 2016 Accepted on October 1, 2016

Correspondence to: Jin Joo Kim, Department of Emergency Medicine, Gachon University Gil Medical Center, 21 Namdong-daero 774beon-gil, Namdong-gu, Incheon 21565, Korea

Tel: +82-32-460-3015, Fax: +82-32-460-3019

E-mail: empear@gilhospital.com

*No potential conflict of interest relevant to this article was reported. es brain injury, a cause of mortality in two-thirds of outof-hospital cardiac arrest (OHCA) patients, [3] myocardial dysfunction and circulatory shock, which are reversible phenomena, ischemia/reperfusion response, which occurs when spontaneous circulation is restored from the stoppage of normal blood flow in the event of CA[4] and persistent precipitating pathology.[5] According to a previous 
study, cardiovascular shock and brain injury are the leading causes of mortality in patients with ROSC after CA, and cardiovascular shock is the most common cause of death in the early stage of hospitalization.[6] Early arterial hypotension is also common after ROSC and is known as a predictor of mortality.[7] Skulec et al.[8] found a higher mortality rate in CA survivors who developed cardiogenic shock during therapeutic hypothermia, when compared with those who did not have the shock. Among the components of PCAS, myocardium dysfunction has been a phenomenon called 'myocardial stunning and reported and studied in clinical research.[9] Myocardium dysfunction (MD) is defined as the reversible reduction of myocardial function despite normal or almost-normal blood flow with no non-reversible lesion, and MD may continue even after myocardial reperfusion.[10] MD is manifested primarily by a diffuse decrease in myocardial force of contraction, extended ischemia and wall thickening on the left ventricle, leading to an increase in enddiastolic volume.[11] The said components of PCAS increase the risk of developing hypotension and multiple organ dysfunction. $[7,12] \mathrm{MD}$ frequently occurs in cardiac arrest survivors but started to recover at $24 \mathrm{~h}$ post-CA and then recovered at 72 h.[13] Many studies reported that MD subsequently results in worsening clinical outcome. However, there have not been enough studies addressing the degree of deterioration and outcomes found. [10] Transthoracic echocardiography (TTE) is a bed-side real-time diagnostic tool used for post-ROSC patients, and the use of this tool in CA patients can be useful for prognostic judgement.[14,15]

The aim of this study was to investigate the impact of initial post-ROSC myocardial dysfunction on mortality and neurological outcome.

\section{Materials and Methods}

\section{1) Study subjects}

This is a retrospective study conducted in a 1,300-bed tertiary care hospital with a 100-bed intensive care unit
(ICU), and nearly 90,000 patients visit the hospital annually. The study included OHCA patients over 18 years of age who were admitted or transferred to our emergency department (ED) and achieved ROSC after cardiopulmonary resuscitation (CPR) before receiving target temperature management during the 24-month period from January 2014 to December 2015. The CPRs were performed in compliance with the guidelines of the U.S Cardiac Association. Subjects were excluded if they died before and within $24 \mathrm{~h}$ of ICU admission, if they refused to take any test or treatment and if their medical records were insufficient.

\section{2) Targeted temperature management (TTM)}

During the study period, therapeutic hypothermia (TH) was performed in OHCA patients with ROSC under a standard protocol. Before undergoing TH, all subjects were orally intubated and mechanically ventilated and had arterial catheters. To achieve the target temperature, ice packs were used along with infusion of $4{ }^{\circ} \mathrm{C}$ normal saline, bladder irrigation and surface cooling methods. Cooling pads (ArcticGel ${ }^{\mathrm{TM}}$ Pads\&ArcticSun ${ }^{\circledR} 2000$, Medivance, CO, USA) or cooling blankets (Blanketrol ${ }^{\circledR}$ II. Cincinnati Sub-Zero Products, Cincinnati, OH, USA) were also used. Patients' temperature was continuously monitored with a rectal transrectal to achieve and maintain the target temperature for $24 \mathrm{~h}$. And then patients were rewarmed at a rate of $0.3{ }^{\circ} \mathrm{C}$ per hour until body temperature reached $36.5^{\circ} \mathrm{C}$, and this rewarming temperature was maintained for $72 \mathrm{~h}$. During TTM, sedatives, analgesics and vecuronium were administered by continuous infusion. TTM was performed with a target of $32-36^{\circ} \mathrm{C}$.

\section{3) Methods}

Our hospital implements the Cardiac Arrest Registry to manage OHCA patients under a systematic approach. Based on the registry, we retrospectively analyzed the records of patients: demographic data including age and sex, medical history, initial rhythm at the time of CA, post-CA Basic Life Support (BLS), Advanced Cardiac Life Support (ACLS), time from arrest to ROSC, acute 
physiology and chronic health evaluation (APACHE) II, echocardiographic findings in ICU, in-hospital mortality, neurological state at discharge and survival days. This study was approved by an IRB. While the patient was lying prone on the bed, TTE was conducted at the bedside in compliance with the requirement that echocardiography must be performed within 48 hours after ICU admission. Each echocardiogram was performed by a physician trained in the use of the device or cardiac sonographer using an echocardiographic scanner (Vivid q ${ }^{\circledR}$, GE Healthcare, Chicago, IL, USA). Using the M-mode transthoracic echo and modified Simpon's rule, left ventricular (LV) internal diameter, interventricular septum, left ventricular end-diastolic diameter (LVEDD), left ventricular endsystolic diameter (LVESD) and left ventricular ejection fraction (LVEF) were measured. LVEF was graded as normal (> 55\%), moderate $(45-55 \%)$ and severe $(<45 \%)$. Patient survival was investigated for up to 90 days, and short-term mortality was measured at 7 days after admission. Neurological outcomes were assessed using a Cerebral Performance Category (CPC) scale, phone calls to patients or their families at 6 months after discharge, and medical records, including records from other medical centers. Neurological outcomes were defined as a CPC 1 (sufficient cerebral function for normal life despite mild injury), CPC 2 (cerebral disability but independent activities of daily life), CPC 3 (conscious but severe cerebral disability, dependent on others for daily support), CPC 4 (coma/vegetative status) and CPC 5 (death) CPC 1-2 is defined as a favorable neurological outcome and CPC 3-5 as a unfavorable neurological outcome.

\section{4) Statistical analysis}

SPSS statics 18.0 (SPSS Inc., Chicago, IL, USA) was used to analyze differences in basic patient characteristics. Resulting data are expressed a mean \pm standard deviation (SD), median \pm interquartile range (IQR) or percentage (\%). In univariate analysis of data, Chi-square and student $t$ test were used, and Mann-Whitney $U$ test was used for continuous variables that are not normally distributed. $P$ value of less than 0.05 was considered statistically significant. Multiple logistic regression analysis was performed to identify factors associated with survival rate and neurological outcome. In all tests, a 95\% confidence interval is constructed for the difference between two-tailed tests with a significant (alpha) level of 0.05 .

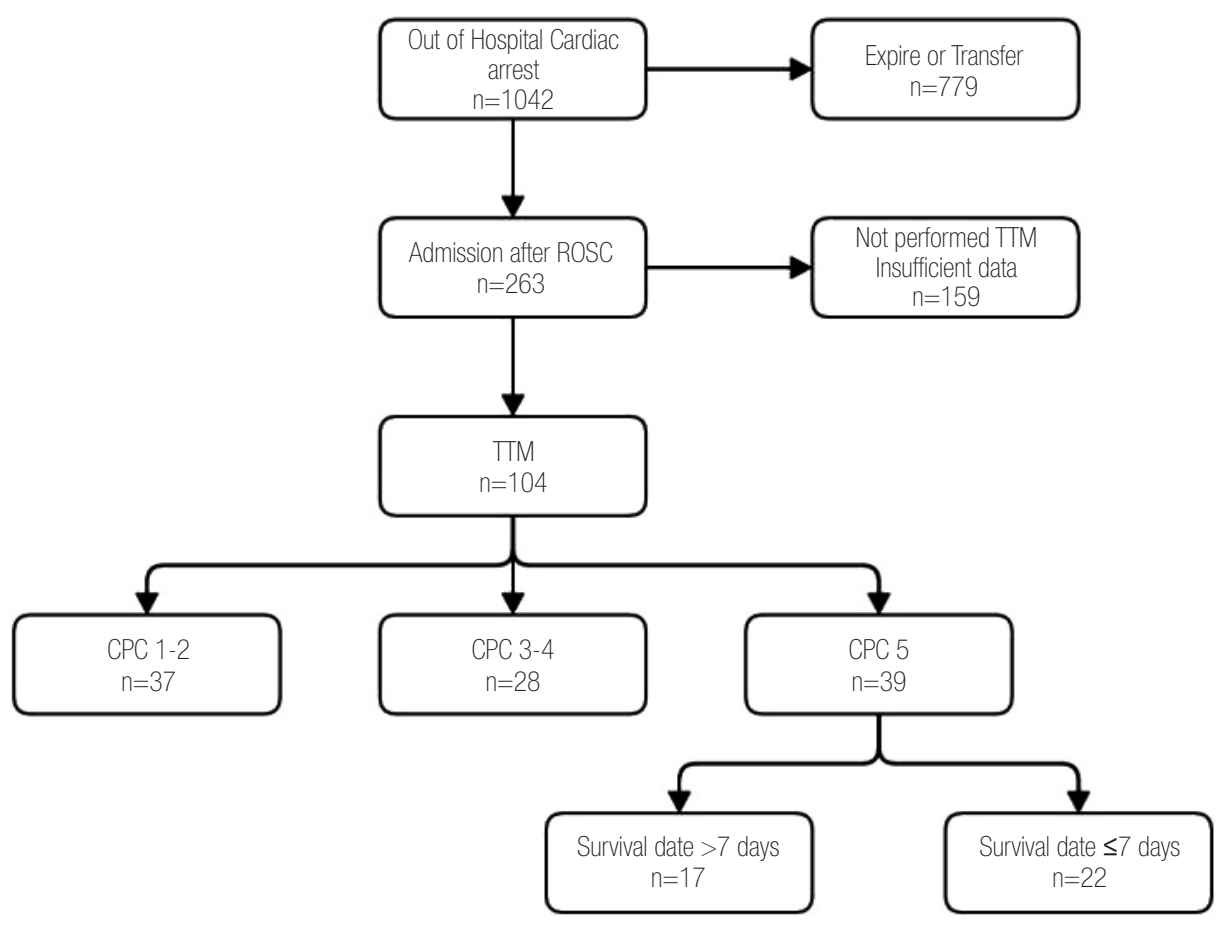

Fig. 1. A flow diagram of the study. ROSC: return of spontaneous circulation; TTM: target temperature management; CPC: cerebral performance category. 


\section{Results}

A total of 1,042 CA patients were admitted to our ED, and 263 of them were admitted to ICU after ROSC. Of those, 104 patients were included in this study, and the remaining patients were excluded because they did not undergo TTM or they were lost to follow-up (Fig. 1).

The patients' mean age was $54.4 \pm 15.3$, and male patients accounted for $72.1 \%$ of total patients. The cause of CA was related to heart in $55(52.9 \%)$ patients, the average time to BLS and ACLS was $8.7 \pm 8.8 \mathrm{~min}$ and $24.0 \pm 12.4 \mathrm{~min}$, respectively. The average time from CA to ROSC was $28.0 \pm 16.1 \mathrm{~min}$. The initial heart rhythm, which is the most commonly identified after CA, was ventricular fibrillation/ventricular tachycardia (39.8\%), followed by asystole (37.9\%) and pulseless electrical activity $(23.3 \%)$ As for medical history, $34.6 \%$ of patients had hypertension and $19.2 \%$ of patients had diabetes. According to TTE results, the largest number of patients had a LVEDD 42-54 mm (65.4\%), a LVESD 24-36 mm $(55.8 \%)$ and a LVEF > 55\% (45.2\%), respectively, in each respective group. At admission, coronary angioplasty (PTCA) was conducted in $19.2 \%$ of patients (Table 1).

During TTE evaluation, hemodynamics in patients showed systolic blood pressure $122.5 \pm 30.0 \mathrm{mmHg}$. diastolic blood pressure $75.2 \pm 18.8 \mathrm{mmHg}$ and heart rate $85.2 \pm 23.7 \mathrm{bpm}$. The mean time to completion of TTE was $16.7 \pm 12.9 \mathrm{~h}$. At the time of TTE, the mean temperature of patients was $34.3 \pm 1.5^{\circ} \mathrm{C}$, and regional wall motion abnormality (RWMA) was observed in $26.9 \%$ of patients.

Based on TTE findings, patients were divided into groups according to prognostic values for neurological outcome at 6 months, mortality at 3 months and mortality at 7 days. In analysis of neurological outcome, 36 patients had favorable CPC and 68 had unfavorable CPC. There were significant differences between favorable and unfavorable outcome groups with respect to initial rhythm during $\mathrm{CA}$, time to ROSC, causes of CA, APACHE II score, blood lactic acid level, coronary angioplasty performed $(\mathrm{p} \leq 0.001,<0.001,<0.001,0.005$, $0.021,0.033)$. Ventricular fibrillation/ventricular tachy-
Table 1. General characteristics of the patients $(N=104)$

\begin{tabular}{|c|c|}
\hline Variable & Value \\
\hline Age (years) & $54.4 \pm 15.3$ \\
\hline \multicolumn{2}{|l|}{ Sex } \\
\hline Female & $29(27.9)$ \\
\hline Male & $75(72.1)$ \\
\hline \multicolumn{2}{|l|}{ Rhythm, initial } \\
\hline Asystole & $39(37.9)$ \\
\hline PEA & $23(23.3)$ \\
\hline VFNT & 41 (39.8) \\
\hline Time to BLS (min) & $8.7 \pm 8.8$ \\
\hline Time to ACLS (min) & $24.0 \pm 12.4$ \\
\hline Time to ROSC (min) & $28.0 \pm 16.1$ \\
\hline \multicolumn{2}{|l|}{ Arrest by } \\
\hline Cardiac origin & $55(52.9)$ \\
\hline Non-cardiac & $49(47.1)$ \\
\hline APACHE ॥ & $26.1 \pm 6.0$ \\
\hline Lactate level just after CPR & $8.4 \pm 3.6$ \\
\hline \multicolumn{2}{|l|}{ Co-morbidity } \\
\hline Hypertension & $36(34.6)$ \\
\hline Diabetes & $20(19.2)$ \\
\hline Heart failure & $4(3.9)$ \\
\hline CAD & $10(9.6)$ \\
\hline Arrhythmia & $8(7.7)$ \\
\hline CVA & $3(2.9)$ \\
\hline COPD/Asthma & $3(2.9)$ \\
\hline CRF & $7(6.7)$ \\
\hline Performed a PCl & 20 (19.2) \\
\hline \multicolumn{2}{|l|}{ TTE findings } \\
\hline $\operatorname{LVEDD}(\mathrm{n}=103)(\mathrm{mm})$ & $46.4 \pm 8.2$ \\
\hline$<42$ & $22(21.2)$ \\
\hline $42-54$ & $68(65.4)$ \\
\hline$>54$ & $14(13.5)$ \\
\hline $\operatorname{LVESD}(n=103)(\mathrm{mm})$ & $34.3 \pm 9.5$ \\
\hline$<24$ & $10(9.6)$ \\
\hline $24-36$ & $58(55.8)$ \\
\hline$>36$ & $36(34.6)$ \\
\hline LV ejection fraction (\%) & $49.5 \pm 17.5$ \\
\hline$<45$ & $39(37.5)$ \\
\hline $45-55$ & $18(17.3)$ \\
\hline$>55$ & $47(45.2)$ \\
\hline
\end{tabular}

Values are presented as mean \pm SD or $n(\%)$.

SD: standard deviation; PEA: pulseless electrical activity; VF: ventricular fibrillation; VT: ventricular tachycardia; BLS: basic life support; ACLS: advanced cardiac life support; ROSC: return of spontaneous circulation; APACHE: acute physiology and chronic health evaluation; CPR: cardiopulmonary resuscitation; CAD: coronary artery disease; CVA: cerebro-vascular accident; COPD: chronic obstructive pulmonary disease; CRF: chronic renal failure; PCl: percutaneous coronary intervention; TTE: transthoracic echocardiography; LVEDD: left ventricular end-diastolic diameter; LVESD: left ventricular end-systolic diameter; LV: left ventricle. 
Table 2. Differences in characteristics by outcome $(N=104)$

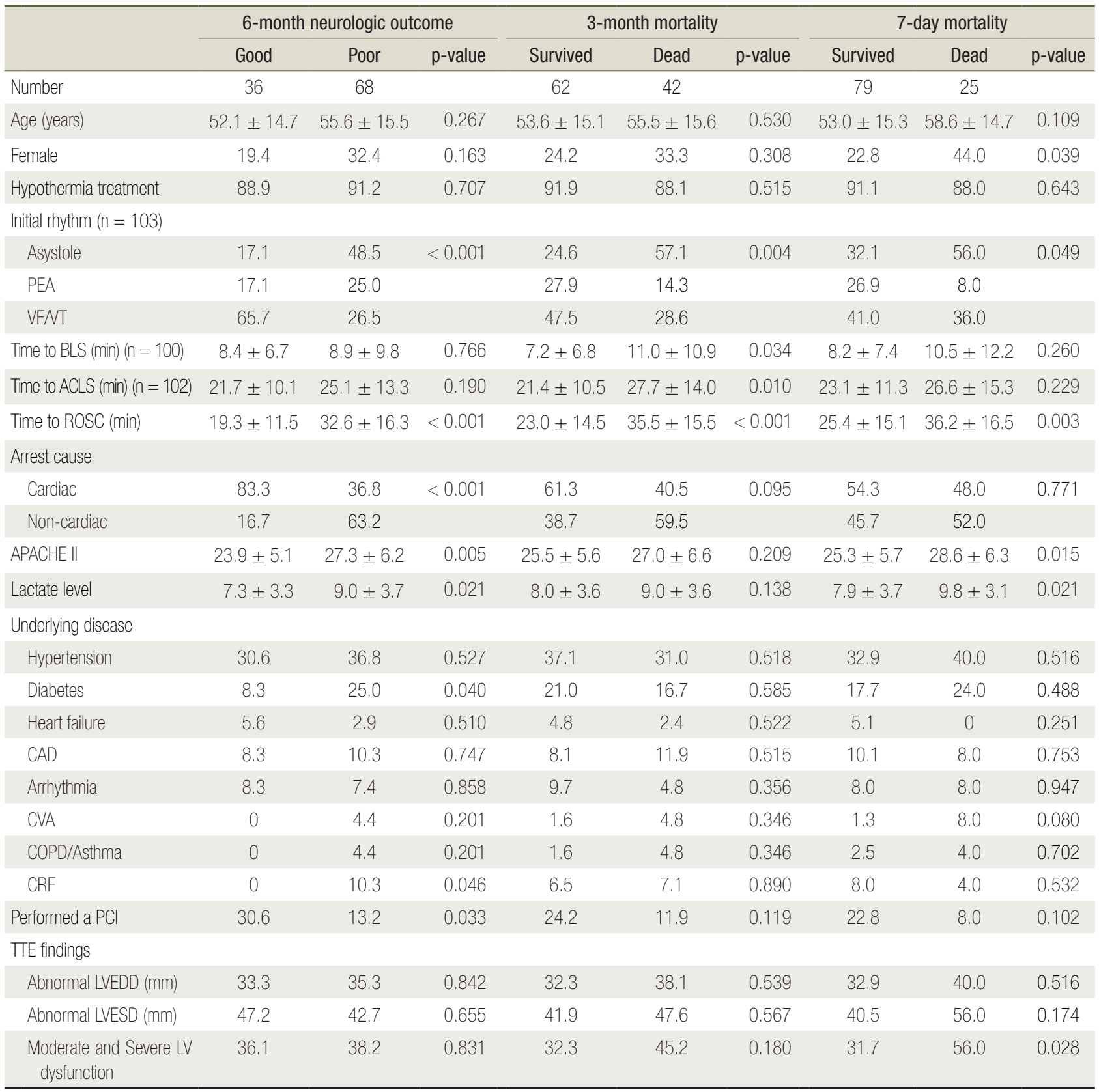

Values are presented as mean \pm SD or $\%$.

PEA: pulseless electrical activity; VF: ventricular fibrillation; VT: ventricular tachycardia; BLS: basic life support; ACLS: advanced cardiac life support; ROSC: return of spontaneous circulation; APACHE: acute physiology and chronic health evaluation; CAD: coronary artery disease; CVA: cerebro-vascular accident; COPD: chronic obstructive pulmonary disease; CRF: chronic renal failure; PCl: percutaneous coronary intervention TTE: transthoracic echocardiography; LVEDD: left ventricular enddiastolic diameter; LVESD: left ventricular end-systolic diameter; LV: left ventricle; SD: standard deviation.

cardia was most common, occurring in $65.7 \%$ of patients with favorable outcome, while asystole was the most common in the unfavorable outcome group $(48.5 \%)$ The mean time to ROSC was $19.3 \pm 11.5 \mathrm{~min}$ in the favorable outcome group and $32.6 \pm 16.3 \mathrm{~min}$ in the unfavorable outcome group. With regard to survival at 3 months after CA, the patients who survived were $62(59.6 \%)$, and those who died were 42 patients (40.4\%). The most com- 
Table 3. Factors associated with 7-day mortality

\begin{tabular}{|c|c|c|c|c|}
\hline & \multicolumn{2}{|c|}{ Univariate } & \multicolumn{2}{|c|}{ Multivariate } \\
\hline & $\mathrm{OR}(95 \% \mathrm{Cl})$ & $\mathrm{p}$-value & $\mathrm{OR}(95 \% \mathrm{Cl})$ & p-value \\
\hline Asystole/PEA (vs. VFNT) & $2.75(1.09-6.91)$ & 0.031 & & \\
\hline Long time to ROSC (per 1 min) & $1.04(1.01-1.07)$ & 0.007 & $1.04(1.00-1.07)$ & 0.034 \\
\hline High APACHE II (per 1) & $1.10(1.02-1.18)$ & 0.018 & $1.10(1.01-1.20)$ & 0.042 \\
\hline High lactate level (per 1 mmol/L) & $1.17(1.02-1.34)$ & 0.025 & & \\
\hline Moderate and Severe LV dysfunction (EF < 45\%) & $2.75(1.09-6.91)$ & 0.031 & $3.02(1.01-9.01)$ & 0.047 \\
\hline
\end{tabular}

OR: odds ratio; Cl: confidence interval; PEA: pulseless electrical activity; VF: ventricular fibrillation; VT: ventricular tachycardia; ROSC: return of spontaneous circulation; APACHE: acute physiology and chronic health evaluation; LV: left ventricle; EF: ejection fraction.

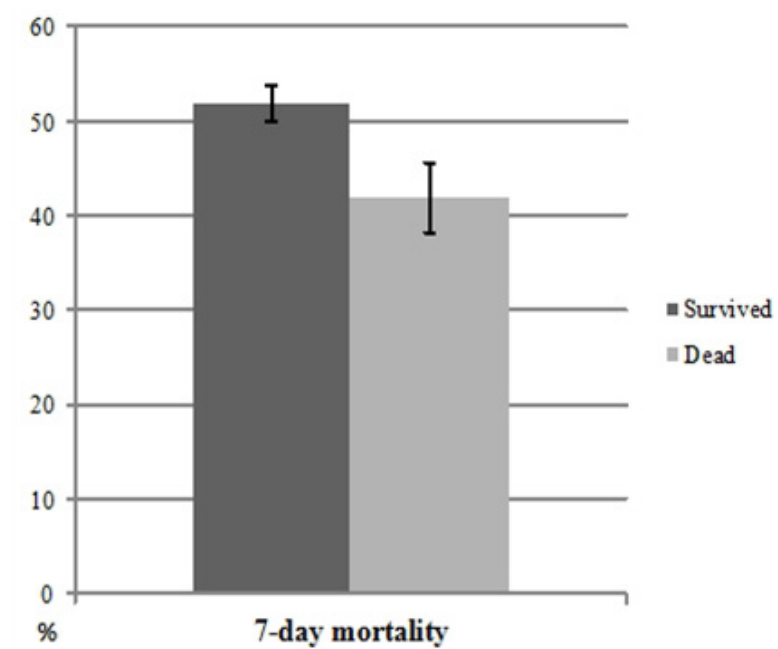

Fig. 2. Adjusted* left ventricular ejection fraction in patients who were alive or dead at the 7-day point. *Adjusted for sex, time to ROSC, and APACHE II score. At the 7-day point after return of spontaneous circulation after cardio-pulmonary resuscitation, LV ejection fraction of survivors was more preserved than that of the dead ( 51.9 vs. $41.9 ; p=0.02$ by multiple regression analysis). Bar represents standard error

mon initial rhythm was ventricular fibrillation/ventricular tachycardia in the survival group (47.5\%) and asystole in the mortality group $(57.1 \%)(\mathrm{p}=0.004)$. The mean time to ROSC was $23.0 \pm 14.5 \mathrm{~min}$ in the survival group and $35.5 \pm 15.5 \mathrm{~min}$ in the mortality group $(\mathrm{p}<0.001)$. With regard to survival at 7 days, 79 (76.0\%) patients survived and $25(24.0 \%)$ died. Severe cardiac dysfunction occurred in $25(31.7 \%)$ of patients survived and $14(56.0 \%)$ of patients dead $(\mathrm{p}=0.028)$ (Table 2).

Multivariate analysis was performed to identify variables that were statistically significant in univariate analysis. Taken together, two variables of time to ROSC and
APACHE II scores were positively associated with mortality, and LVEF $<45 \%$ were associated with increased mortality within 7 days after CA (odds ratio [OR] 1.04 [95\% confidence interval (CI), 1.00-1.07], OR 1.10 [95\% CI, 1.01-1.20], OR 3.02 [95\%CI, 1.01-9.08]) (Table 3, Fig. 2).

\section{Discussion}

In the present study, we identified the association between left ventricular function and short-term mortality in OHCA patients. Neurological outcome is one of the leading causes of death in OHCA patients with ROSC, and post-CA shock is another leading cause of death for them. $[3,16]$ Post CA shock is characterized by ischemia/ reperfusion injury of the brain or other organs after ROSC in CA survivors.[14]

Laver et al.[3] stated that brain injury was the most common cause of death in patients with ROSC after CA by citing the mortality rate of $66.7 \%$ in OHCA patients and $22.9 \%$ in in-hospital CA patients. In another study, Herlitz et al.[17] claimed brain injury alone was the leading cause of death in CA patients (45\%), followed by injuries of heart and brain (40\%) and heart injury (9\%).

Among some studies that reviewed prognostic factors in post CA patients, Bro-Jeppesen et al.[18] identified the average arterial pressure as an predictor of 30-mortality in their retrospective randomized study of hemodialysis and vasoconstrictor in 920 OHCA patients who underwent TTM. They added that the mean arterial pressure of 
$65 \mathrm{mmHg}$ or lower increased the mortality rate and that the proportion of LVEF $<30 \%$ was higher in patients with lower mean arterial pressure.[18] Also, Thomsen et al.[19] reported bradycardia as a favorable prognostic factor for 180-day survival and favorable outcome in 234 patients who received TTM after psychogenic OHCA with ROSC and that the mean LVEF was higher by nearly $5 \%$ in patients with bradycardia, compared with the group without bradycardia. They also assumed that slowed heart rate after TTM lengthens diastolic time and reduces oxygen consumption, allowing for maintenance of myocardial function and favorable outcome at the end.[20]

In CA patients, myocardial dysfunction represents a form of ischemia and reperfusion injury extensively occurred in CA patients after ROSC. MD is associated with mutual activation of underlying cardiac pathophysiology and myocardial injury during CA.[14] In their study investigating the association between $\mathrm{MD}$ and prognosis, Laurent et al.[21] reported that 73 (44.2\%) of total 165 CA patients with ROSC were hemodynamically unstable in the early stage after admission (average $6.8 \mathrm{~h}$ ), and 59 of them showed recovery from MD after $24 \mathrm{~h}$. However, the remaining 12 unrecovered patients died from multiple organ failure in the early stage of admission.

According Palmer et al.[22], continued CPR has adverse impact on the left ventricle in a time dependent way at a later stage, and Xie et al.[23] also claimed the time-dependent adverse effects of defibrillation on the left ventricle. Separately, Chang et al.[14] suggested that LVEF level at $6 \mathrm{~h}$ after CA and isovolumic relaxation time are associated with patient survival rate.[15] In a study of cardiac index and neurological outcome, Torgersen et al.[24] reported a higher cardiac index in favorable neurological outcome group, compared with unfavorable neurological outcome group, suggesting the association between cardiac indexes and neurological outcome. In another study looking at the association between cardiac function and mortality, Fincke et al.[25] reported that cardiac output and the average arterial pressure were associated with increased mortality in patients with cardiogenic shock. In their study, LVEF was also investigated but this was not statistically significant.[25]

Thus many studies have investigated the mortality and prognosis in OHCA patients, but not many studies have been carried out concerning echocardiographic findings. Gonzalez et al.[26] looked at the results of TTE conducted before and after CA to determine the association between left ventricular systolic function and outcome in in-hospital CA patents and found that $49(58.3 \%)$ of total 84 patients had a LVEF $<45 \%$ in TTE and that patients who had low left ventricular systolic function before CA demonstrated lower survival rate than patients with normal systolic function and showed further sever MD after CA. Ameloot et al.[27] reported the mean left ventricular cardiac output of $42 \%$ in 82 CA patients and $34 \%$ in patients with low venous oxygen saturation. The cardiac output of $42 \%$ is similar to that we found in the present study, in which sever MD occurred in 39 (37.5\%) out of 104 OHCA patients with ROSC.

In summary, a variety of functional abnormalities occur immediately after ROSC in PCAS patients, and physicians should be attentive to MD to come up with treatment strategy. Severe MD, albeit temporary, can increase short-term mortality. In this study, MD was not significantly associated with 90-day mortality and neurological outcome, and this non-significant result is presumably due to the possibility that mortality rates in PCAS patients result from a combination of factors such as neurologic insult, in addition to myocardial dysfunction. Also, no significant association was found between LV dimensions and outcome in this study. This finding suggests that LV size may be affected by not only CA and CPR process but also pre-existing conditions before $\mathrm{CA}$ and that LV size itself may not be a good proxy for LV's overall function.

This study has the following limitations: First, this is a retrospective study, and subjects were limited to patients treated at a single institution. However, by using CPR data that were systematically collected through the registry, we could minimize bias. Secondly, as several physicians, albeit trained in cardiology, read echocardiograms, differences in results cannot be ruled out. Thirdly, this 
study did not address the effects of inotropic agents and vasopressors, suggesting the need for further research. The limited number of patient cases can also pose a limitation.

Among components of PCAS, moderate or severe left ventricular dysfunction manifested by LVEF $<45 \%$ was found to be an independent prognostic factor for 7-day mortality although this component was not statistically related to 90-day mortality and neurological outcome. If LVEF is dropping in patients with PCAS, intravenous fluid and vasopressor can be therefore administered and mechanical intervention such as ECMO can be applied, if necessary. Further multicenter studies are needed to confirm these suggestions.

\section{ORCID}

Jin Joo Kim http://orcid.org/0000-0002-5678-2019

Hyuk Jun Yang http://orcid.org/0000-0001-8324-9749

\section{References}

1) Jacobs I, Nadkarni V, Bahr J, Berg RA, Billi JE, Bossaert L, et al: Cardiac arrest and cardiopulmonary resuscitation outcome reports: update and simplification of the Utstein templates for resuscitation registries. A statement for healthcare professionals from a task force of the international liaison committee on resuscitation (American Heart Association, European Resuscitation Council, Australian Resuscitation Council, New Zealand Resuscitation Council, Heart and Stroke Foundation of Canada, InterAmerican Heart Foundation, Resuscitation Council of Southern Africa). Resuscitation 2004; 63: 233-49.

2) Nolan JP, Neumar RW, Adrie C, Aibiki M, Berg RA, Böttiger BW, et al: Post-cardiac arrest syndrome: epidemiology, pathophysiology, treatment, and prognostication A Scientific Statement from the International Liaison Committee on Resuscitation; the American Heart Association Emergency Cardiovas- cular Care Committee; the Council on Cardiopulmonary, Perioperative, and Critical Care; the Council on Clinical Cardiology; the Council on Stroke. Resuscitation 2008; 79: 350-79.

3) Laver S, Farrow C, Turner D, Nolan J: Mode of death after admission to an intensive care unit following cardiac arrest. Intensive Care Med 2004; 30 : 2126-8.

4) Adrie C, Laurent I, Monchi M, Cariou A, Dhainaou JF, Spaulding C: Postresuscitation disease after cardiac arrest: a sepsis-like syndrome? Curr Opin Crit Care 2004; 10: 208-12.

5) Kürkciyan I, Meron G, Sterz F, Janata K, Domanovits $\mathrm{H}$, Holzer M, et al: Pulmonary embolism as cause of cardiac arrest: presentation and outcome. Arch Intern Med 2000; 160: 1529-35.

6) Lemiale V, Dumas F, Mongardon N, Giovanetti O, Charpentier J, Chiche JD: Intensive care unit mortality after cardiac arrest: the relative contribution of shock and brain injury in a large cohort. Intensive Care Med 2013; 39: 1972-80.

7) Kilgannon JH, Roberts BW, Reihl LR, Chansky ME, Jones AE, Dellinger RP: Early arterial hypotension is common in the post-cardiac arrest syndrome and associated with increased in-hospital mortality. Resuscitation 2008; 79: 410-6.

8) Skulec R, Kovarnik T, Dostalova G, Kolar J, Linhart A: Induction of mild hypothermia in cardiac arrest survivors presenting with cardiogenic shock syndrome. Acta Anaesthesiol Scand 2008; 52: 188-94.

9) Gerber BL, Wijns W, Vanoverschelde JL, Heyndrickx GR, De Bruyne B, Bartunek J, et al: Myocardial perfusion and oxygen consumption in reperfused noninfarcted dysfunctional myocardium after unstable angina angina: direct evidence for myocardial stunning in humans. J Am Coll Cardiol 1999; 34: 1939-46.

10) Ruiz-Bailén $M$, Aguayo de Hoyos E, Ruiz-Navarro $S$, Díaz-Castellanos MA, Rucabado-Aguilar L, GómezJiménez FJ, et al: Reversible myocardial dysfunction after cardiopulmonary resuscitation. Resuscitation 
2005; 66: 175-81.

11) Ayoub IM, Kolarova J, Yi Z, Trevedi A, Deshmukh H, Lubell DL, et al: Sodium-hydrogen exchange inhibition during ventricular fibrillation: beneficial effects on ischemic contracture, action potential duration, reperfusion arrhythmias, myocardial function, and resuscitability. Circulation 2003; 107: 1804-9.

12) Robert BW, Kilgannon JH, Chansky ME, Mittal N, Wooden J, Parrillo JE, et al: Multiple organ dysfunction after return of spontaneous circulation in postcardiac arrest syndrome. Crit Care Med 2013; 41: 1492-501.

13) Chalkias A, Xanthos T: Pathophysiology and pathogenesis of post-resuscitation myocardial stunning. Heart Fail Rev 2012; 17: 117-28.

14) Chang WT, Ma MH, Chien KL, Huang CH, Tsai MS, Shih FY, et al: Postresuscitation myocardial dysfunction: correlated factors and prognostic implications. Intensive Care Med 2007; 33: 88-95.

15) Price S, Uddin S, Quinn T: Echocardiography in cardiac arrest. Curr Opin Crit Care 2010; 16: 211-5.

16) Lemiale V, Dumas F, Mongardon N, Giovanetti O, Charpentier J, Chiche JD, et al: Intensive care unit mortality after cardiac arrest: the relative contribution of shock and brain injury in a large cohort. Intensive Care Med 2013; 39: 1972-80.

17) Herlitz J, Ekstrtöm L, Wennerblom B, Axelsson A, Bång A, Holmberg S: Hospital mortality after out-ofhospital cardiac arrest among patients found in ventricular fibrillation. Resuscitation 1995; 29: 11-21.

18) Bro-Jeppesen J, Annborn M, Hassager C, Wise MP, Pelosi P, Nielsen N, et al: Hemodynamics and vasopressor support during targeted temperature management at $33^{\circ} \mathrm{C}$ Versus $36^{\circ} \mathrm{C}$ after out-of-hospital cardiac arrest: a post hoc study of the target temperature management trial. Crit Care Med 2015; 43: 318-27.

19) Thomsen JH, Hassager C, Bro-Jeppesen J, Søholm H, Nielsen N, Wanscher M, et al: Sinus bradycardia during hypothermia in comatose survivors of out-ofhospital cardiac arrest - a new early marker of favorable outcome? Resuscitation 2015; 89: 36-42.

20) Jacobshagen C, Pelster T, Pax A, Horn W, Schweda SS, Unsöld BW, et al: Effects of mild hypothermia on hemodynamics in cardiac arrest survivors and isolated failing human myocardium. Clin Res Cardiol 2010; 99: 267-76.

21) Laurent I, Monchi M, Chiche JD, Joly LM, Spaulding $\mathrm{C}$, Bourgeois $\mathrm{B}$, et al: Reversible myocardial dysfunction in survivors of out-of-hospital cardiac arrest. J Am Coll Cardiol 2002; 40: 2110-6.

22) Palmer BS, Hadziahmetovic M, Veci T, Angelos MG: Global ischemic duration and reperfusion function in the isolated perfused rat heart. Resuscitation 2004; 62: 97-106.

23) Xie J, Weil MH, Sun S, Tang W, Sato Y, Jin X, et al: High-energy defibrillation increases the severity of posresuscitation myocardial dysfunction. Circulation 1997; 96: 683-8.

24) Torgersen C, Meichtry J, Schmittinger CA, Bloechlinger S, Jakob SM, Takala J, et al: Haemodynamic variables and functional outcome in hypothermic patients following out-of-hospital cardiac arrest. Resuscitation 2013; 84: 798-804.

25) Fincke R, Hochman JS, Lowe AM, Menon V, Slater $\mathrm{JN}$, Webb JG, et al: Cardiac power is the strongest hemodynamic correlate of mortality in cardiogenic shock: a report from the SHOCK trial registry. J Am Coll Cardiol 2004; 44: 340-8.

26) Gonzalez MM, Berg RA, Nadkarni VM, Vianna CB, Kern KB, Timerman S, et al: Left ventricular systolic function and outcome after in-hospital cardiac arrest. Circulation 2008; 117: 1864-72.

27) Ameloot K, Meex I, Genbrugge C, Jans F, Boer W, Verhaert $\mathrm{D}$, et al: Hemodynamic targets during therapeutic hypothermia after cardiac arrest: a prospective observational study. Resuscitation 2015; 91: 56-62. 